International Journal of Maternal and Child Health and AIDS (2020), Volume 9, Issue I, 77-80

\begin{tabular}{ll}
\hline & INTERNATIONAL JOURNAL of \\
& MATERNAL and CHILD HEALTH and AIDS \\
& ISSN 216I-864X (Online) \\
& ISSN 216I-8674 (Print) \\
IJMA Available online at www.mchandaids.org & DOI: 10.21 I 06 /ijma.295 \\
\hline
\end{tabular}

COMMENTARY

\title{
Addressing Supply Chain Management Issues in Cost-effective Maternal and Pediatric Global Surgery:A Call to Action
}

\author{
Sergio M. Navarro, MBA; ${ }^{1,2,3 凶}$ Andile Sibiya, MBChB, FCORL, MBA; ${ }^{2}$ Maziar M. Nourian, MD; ${ }^{3,4}$ \\ Kelsey A. Stewart, MD; 5 Taylor D. Ottesen, BS; ;,6 Raymond R. Price, MD ${ }^{7}$ \\ 'Department of Surgery, Baylor College of Medicine, Houston,TX, USA; ${ }^{2}$ Said Business School, University of Oxford, Oxford, UK; ${ }^{3}$ Global Surgery \\ Student Alliance (GSSA), Boston, MA, USA; ${ }^{4}$ Department of Anesthesia, Vanderbilt School of Medicine, Nashville, TN, USA; ${ }^{5}$ Department of Obstetrics and \\ Gynecology, University of Minnesota, Minneapolis, MN, USA; ${ }^{6}$ Department of Orthopedics and Rehabilitation, Yale University School of Medicine, \\ New Haven, CT, USA; ${ }^{7}$ Center for Global Surgery, University of Utah, Salt Lake City, UT, USA \\ Corresponding author email: mnavarro@alum.mit.edu
}

\section{ABSTRACT}

Persistent global disparities in maternal and neonatal outcomes exist, in part, due to a lack of access to safe surgery. This commentary examines the relative need for increased focus on access to safe maternal and pediatric surgery globally, starting with a focus on cost-effective surgeries. There is a need to understand context-specific surgeries for regions, including understanding regional versus tertiary development. Most important is a need to understand the crucial role of supply chain management (SCM) in developing better access to maternal and pediatric surgery in limited resource settings. We evaluate the role of SCM in global surgery and global health, and the current landscape of inefficiency. We outline specific findings and takeaways from recent solutions developed in pediatric and maternal surgery to address SCM inefficiencies. We then examine the applicability to other settings and look at the future. Our goal is to summarize the challenges that exist today in a global setting to provide better access to maternal and pediatric surgery and outline solutions relying on structural, SCM-related framework.

Key words: • Pediatric surgery • Neonatal outcomes $\bullet$ Supply-chain management $\bullet$ Limited resource settings

Copyright () 2020 Navarro et al. Published by Global Health and Education Projects, Inc. This is an open-access article distributed under the terms of the Creative Commons Attribution License CC BY 4.0.

\section{Introduction}

The Lancet Commission on Global Surgery has outlined the need for safe, timely, and affordable surgical care around the world. The commission's Global Surgery 2030 reported that of the 7.7 billion people worldwide, 5 billion lack access to safe, essential, life-saving surgical and anesthesia care, many in low and middle-income countries.' But, within these numbers lies another staggering trend outlining a need for access to surgical resources for women and children. The World Health Organization (WHO) has reported that 1.7 billion of the 2.54 billion children and teenagers around the world lack access to safe, timely, and affordable surgical care. ${ }^{2,3}$. The 2.4 billion people lacking access to safe surgery are female, women and children representing an estimated 3.3 billion, or $70 \%$ of the total need. ${ }^{4}$ Literature has described the cost-effectiveness of key maternal and pediatric surgeries. ${ }^{5,6}$ We examine 
the most cost-effective surgeries in maternal and pediatric surgery globally and identify key supply chain issues preventing delivery of those procedures.

\section{Focus on Cost-effective Surgeries}

Of the needed surgical care in maternal and pediatric surgery,focus on cost-effective surgeries would provide the largest economies of scale relative to the cost of increasing access. In pediatric care, Saxton identified inguinal hernia repair, trichiasis surgery, and specific orthopedic surgical procedures with the lowest costeffectiveness ratios. ${ }^{7}$ In gynecology, the benefits of fistula surgery at $\$ 54$ cost per Disability Adjusted Life Years (DALY) averted are the lowest. ${ }^{8}$ In maternal surgery, emergency obstetric care in the form of cesarean sections and safe first trimester termination has been increasingly established. ${ }^{5,6} \mathrm{~A}$ lack of access to emergency obstetric services merits immediate action, with more than $15 \%$ of women in labor requiring cesarean delivery. ${ }^{9}$ Furthermore, significant maternal and neonatal morbidity and mortality may result, including obstetric fistula., 80 Of potential procedures for safe termination, manual vacuum aspiration (MVA) is reported as the most cost-effective, compared to dilation and curettage (D\&C). ${ }^{5}$

\section{Context Targeted Surgeries for Areas: Regional vs Tertiary}

Healthcare systems internationally need to be better understood before developing plans to access safe surgery. For example, South Africa's tiered system results in different budgets available for procedures considered primary health care level, compared to a regional or tertiary level. Tertiary service grants are awarded separately to provincial department of health funds." This system impacts the equipment and services available at each hospital level. Whilst surgical teams may have the expertise and equipment, key support services such as specialists, anesthetics, and the availability of a pediatric Intensive Care Units (ICU) will impact the type of surgery. Analysis of systematic and environmental barriers in regards to access is important before attempted implementation.

\section{Role of Supply Chain Management}

A key issue facing global surgery, and global healthcare delivery more broadly, lies in the structural inefficiencies which prevent the timely delivery of a supply of products and services to the appropriate settings for conduct of surgical procedures. ${ }^{12,13}$ The global health care supply chain is a complex, dynamic network of systems composed of materials, information, and financing. 12,14 Many believe that the current health care delivery system requires a fundamental restructuring to create value improvement. ${ }^{15}$ With supply chain management (SCM) emerging to incorporate a scope beyond traditional logistics functions, and increasingly applied to health care systems, we believe that addressing key SCM challenges in global surgery will increase access to safe surgery. The United States Agency for International Development (USAID) has created a comprehensive SCM program to increase global health care delivery, including region-specific interventions and education of the future SCM workforce. ${ }^{15}$ These interventions are of particular importance in global surgery where procurement processes differ from hospital to hospital. An understanding of "cost-effectiveness" by a remotely placed SCM official may be weighted largely on absolute costs and maintenance contracts, whilst the surgical team may have important insights into durability, efficacy, and fit-for-purpose metrics.

\section{Improving SCM Globally}

An integral part of improving access to safe surgery for maternal and pediatric populations is raising the quality of anesthetic care globally. Calls for improvement of SCM and innovative technologies exist with the growing market of anesthesia devices globally. ${ }^{16,17}$ In anesthesia, medication SCM is key to the development of a national surgical plan as observed in a study in Madagascar. ${ }^{18}$ In order to meet safety demands, the World Federation of Societies of Anesthesiologists (WFSA) and WHO have designed international standards for safer anesthesia. Further recommendations should include SCM. ${ }^{19}$ In obstetric surgical care, the role of medication SCM is also key, just as the ready availability of essential obstetric medications, such as uterotonics, may reduce maternal mortality during delivery. ${ }^{20,21}$

\section{Applicability of SCM}

The applicability of SCM extends to many specialties beyond pediatric and obstetric surgery. For example, 
in Zimbabwe and Ghana there is variability in the quality of orthopedic implants as they are retrieved through a variety of methods including: direct purchase from an external supplier; procurement from an intermediate dispensary; and global partnership donations. ${ }^{22}$ SCM could possibly lead to leveraging existing partnerships with the private sector. For example, the equipment can be provided to the hospital on loan, enabling surgery. Additionally, good SCM means partnership agreements among departments and hospitals, as well as sharing of resources via equipment stacking and pooling. This reduces the overall financial burden to the hospital, and maximizes service delivery. Lastly, electricity inconsistency affects all surgical specialties and leads to unnecessary complications and mortality in the emergency setting. ${ }^{23}$ With less than two-thirds of hospitals having a continuous primary or back-up electrical supply, SCM may address this need. ${ }^{24}$

\section{Looking Ahead}

Benefits in maternal and pediatric global surgery could result from implementing SCM training programs. A realistic understanding of budgetary constraints is needed, alongside an approach that maximizes benefits for all stakeholders. Furthermore, a systematic SCM framework can improve surgical outcomes and increase access to safe surgery beyond the operating room. Mapping the surgery ecosystem on a regionally-specific basis helps to implement equipment maintenance programs, empower local teams, and involve key stakeholders. Partnership of SCM workers with global surgeons in obstetric and pediatric surgery can further improve supply chain workforce functions and productivity.

\section{Compliance with Ethical Standards}

Competing Interests: The authors declare that they have no competing interest. Ethics approval: Not required.

\section{Key Messages}

Development of supply chain management (SCM) solutions in a structured framework including training programs and partnerships can enable access to maternal and pediatric surgery, particularly in limited resource settings.

\section{References}

I. The Lancet Commission on Global Surgery. Global Surgery 2030.; 2015.

2. Mullapudi B, Grabski D, Ameh E, et al. Estimates of number of children and adolescents without access to surgical care. Bull World Health Organ. 2019;97(4):254-258. doi:10.247I/BLT.18.216028.

3. World Bank. DataBank - World Development Indicators. World Bank national accounts data, and OECD National Accounts data files.

4. Kaseje N.WHO Emergency and Essential Surgical Care Programme, Technical Meeting on Surgical, Obstetric and Anaesthesia Care. In: $72^{\text {nd }}$ World Health Assembly, Meeting Report.; 2019.

5. Prinja S, Nandi A, Horton S, Levin C, Laxminarayan R. Costs, Effectiveness, and Cost-Effectiveness of Selected Surgical Procedures and Platforms. In: Disease Control Priorities, Third Edition (Volume 1): Essential Surgery.; 20I6. doi:I0.1596/978-I-46480346-8_ch 18

6. Horton S, Levin C.Cost-Effectiveness of Interventions for Reproductive, Maternal, Neonatal, and Child Health. In: Disease Control Priorities, Third Edition (Volume 2): Reproductive, Maternal, Newborn, and Child Health.; 20 I6. doi:I0.1596/978-I-4648-0348-2_chI7

7. Saxton AT, Poenaru D, Ozgediz D, et al. Economic analysis of children's surgical care in low- and middleincome countries: A systematic review and analysis. PLoS One. 2016. doi:10.1371/journal.pone.0165480

8. Epiu I, Alia G, Mukisa J, Tavrow P, Lamorde M, Kuznik A. Estimating the cost and cost-effectiveness for obstetric fistula repair in hospitals in Uganda: A low income country. Health Policy Plan. 2018. doi:10.1093/heapol/czy078

9. Guilmoto CZ, DumontA.Trends, RegionalVariations, and Socioeconomic Disparities in Cesarean Births in India, 20 10-2016.JAMA Netw open. 2019. doi:10.100 I/ jamanetworkopen.2019.0526

10. Institute of Medicine (US) Committee on Improving Birth Outcomes. Improving Birth Outcomes: Meeting the Challenge in the Developing World.; 2003.

II. Mclntyre D, Doherty J, Ataguba J. Universal health coverage assessment: South Africa. Global Network for Health Equity. 2014.

II. Case H.The Global Health Supply Chain. 2012:1-22.

12. Singh M.MIT Center for Transportation and Logistics 
Transforming the Global Health Care Supply Chain. Transportation (Amst). 2006: I-I I.

13. Privett N, Gonsalvez D. The top ten global health supply chain issues: Perspectives from the field. Oper Res Heal Care. 20I4. doi:I0.1016/j.orhc.2014.09.002

14. Byrnes J (HBSWK). Fixing the Healthcare Supply Chain.; 2004.

15. Global U, Supply H, Program C. Procurement and Supply Management FISCAL YEAR 2019.2019.

16. Harris MJ.We Need More Reports of Global Health Anesthesia Articles. Anesthesiology. 2016; 124(2):267269. doi: 10.1097/aln.0000000000000954

17. 360 Market Updates. Anesthesia Devices Market 2019 Global Industry Size, Outlook, Share, Demand, Manufacturers and 2023 Forecast. NBC News. https://www.nbc-2.com/story/4053029l/anesthesiadevices-market-2019-global-industry-size-outlookshare-demand-manufacturers-and-2023-forecast. Published 2019.Accessed June 15, 2019.

18. Baxter LS, Ravelojaona VA, Rakotoarison HN, et al. An observational assessment of anesthesia capacity in Madagascar as a prerequisite to the development of a national surgical plan. Anesth Analg. 2017;124(6):2001-2007. doi:10.1213/ ANE. 0000000000002049

19. Gelb AW, Morriss WW, Johnson W, Merry AF.World Health Organization-World Federation of Societies of Anaesthesiologists (WHO-WFSA) international standards for a safe practice of anesthesia. Anesth Analg. 2018;126(6):1-9. doi:10.1213/ ANE. 0000000000002927

20. Kartoglu U, Widmer M, Gulmezoglu M. Stability of oxytocin along the supply chain: A WHO observational study. Biologicals. 2017;50:117-124. doi:I0.10I6/j.biologicals.2017.05.004

21. Hounton SH, Newlands D, Meda N, De Brouwere $V$. A cost-effectiveness study of caesarean-section deliveries by clinical officers, general practitioners and obstetricians in Burkina Faso. Hum Resour Heal [Electronic Resour. 2009;7:34. doi: https://dx.doi. org// 0.1 I86/I478-449I-7-34

22. Sekyonda Z, Reid A, Mwaka ES, et al. Supply chain of routine orthopaedic implants in Kampala, Uganda: public-private workarounds arising from poverty and scarcity. Glob Heal Innov. 20 I8; I ( I): I - I0. doi:I0.I564I/ghi.vlil.448

23. Marisa J, Uzhenyu D. Electricity Power Supply Shortage on Health Service Delivery of Health Institutions in Harare, Zimbabwe (2010-2015). IOSR J Bus Manag Ver IV. 20I7;19(10):2319-7668. doi:10.9790/487X-1910045868

24. Chawla S, Kurani S, Wren SM, et al. Electricity and generator availability in LMIC hospitals: improving access to safe surgery.J Surg Res. 2018;223:136-14I. doi:10.1016/j.jss.2017.10.016 